\title{
EFFECTS OF EGO-INVOLVEMENT CONDITIONS ON ATTITUDE CHANGE TO HIGH AND LOW CREDIBILITY COMMUNICATORS ${ }^{1}$
}

\author{
HOMER H. JOHNSON 2 AND JOHN A. SCILEPPI
}

Loyola University, Chicago, Illinois

\begin{abstract}
In a $2 \times 2 \times 2$ design, male high school students received from a high or low credibility source a communication that was either plausible or implausible, and that was given under high- or low-ego-involvement conditions. Results indicated greater attitude change in low-ego-involvement-high-sourcecredibility conditions than in the other three combinations of source credibility and ego involvement. These latter three combinations did not differ significantly from each other. Results supported the theory that source credibility is a "set" influencing communication acceptance-rejection primarily under low-ego-invalvement conditions. Extension of the theory to social conformity experiments is discussed.
\end{abstract}

That high credibility sources elicit more attitude change than do low credibility sources is one of the most consistent findings in the attitude-change literature. In spite of this consistency, or perhaps because of this consistency, little attempt has been made to develop an explanation of source-credibility effects. Most attitude research is run under somewhat low-ego-involvement conditions, and for these conditions it is hypothesized that source credibility does not effect attention to, or comprehension of, the communication but rather operates as an evaluative "set" influencing the subject's acceptance or rejection of the content of the communication. With high source credibility the subject is generally accepting the content of the communication and does not evaluate it critically nor generate counterarguments. With low source credibility there is a tendency to reject the content, to feel that the arguments are biased or incomplete, and probably there is some generation of counterarguments.

If source credibility is operating as a set as described above under low-ego-involving conditions, then by creating conditions in which

\footnotetext{
1 This research was supported by National Science Founclation Grant G-1329 to the senior author. Appreciation is expressed to Brother Patrick Cestaro, principal of Marist High School, for his cooperation in the execution of this study.

3 Requests for reprints should be sent to Homer H. Johnson, Department of Psychology, Loyola University, 6525 North Sheridan Road, Chicago, Illinois 60626
}

all subjects are evaluating the communication in a critical manner (i.e., a high-ego-involvement treatment), we should find no difference in attitude change to high and low credibility sources. Furthermore, if high-ego-involvement conditions activate a critical set similar to that which operates with a low credibility source under low-ego-involvement conditions, then it is hypothesized that there should be no difference in attitude change to either source under high-ego-involvement conditions and the low credibility source under low egoinvolvement conditions. However, attitude change to the high credibility source under low-ego-involvement conditions should be greater than in the other three combinations of source credibility and ego involvement listed earlier.

A second problem to be explored is the effect of communication plausibility on attitude change to high and low credibility sources. This problem has not been explored; in fact, implausible communications rarely have been used in attitude research. In discussing source effects under apparently lowego-involving conditions, Hovland, Janis, and Kelly (1953) have suggested that "source credibility has its maximum effects on acceptance when the source and the content are such that there would be considerable discrepancy between the attitudinal responses to each of them alone [p. 41]." It would seem from this statement that the difference between a high and low source on a plausible communication 
would be the same as a high and low source on an implausible communication since both cases contain a source-communication discrepancy. However, the authors further consider a limitation to this generalization; that is, with a high source implausible communication, the subject may dissociate the source from the content by disbelieving that the source actually gave the communication. If dissociation does occur, then a plausible communication should elicit greater source differences than an implausible communication. This study will also explore the effects of communication plausibility on attitude change to high and low credibility sources as well as test for dissociation effects.

\section{METHOD \\ Design and Subjects}

A $2 \times 2 \times 2$ design was used with subjects receiving a communication arguing against the use of chest $\mathrm{X}$ rays for the detection of tuberculosis. The communication was attributed to either a high or a low credibility source, was of high or low plausibility, and was given under high- or low-ego-involvement conditions. Two control groups were used. These control groups did not receive any communication but simply checked the posttreatment attitude after receiving high- or low-ego-involvement conditions.

Subjects were students at a male parochial high school in Chicago. They were tested during their regularly scheduled class or study hall periods. There were 25 subjects in each of the 10 treatment groups.

\section{Independent Variables}

Ego-involvement conditions. On the second page of the test booklet the subjects read a statement that was proported to be the purpose of the study. For the low-ego-involvement condition, the purpose was stated as:

The study you are participating in is mostly of an experimental nature. We are not interested in your opinions or your attitudes. We are mainly interested in whether the materials used in this booklet are reliable and would be useful in studies that we are planning for the future.

For the high-ego-involvement condition, the purpose was stated as:

This study is part of some very important research we are doing for the National Science Foundation. We are primarily concerned with the ability of high school students to make sound and intelligent judgments to materials used in public communications. Some people have said that high school students do not have the ability to make intelligent judgments. Other people have argued that high school students have as good ability to make sound judgments as educated adults. The purpose of this study is to see which of these two viewpoints is true. It is extremely important that you read the materials carefully and be thoughtful in answering the questionnaires.

Source credibility. After receiving the purpose of the study (ego-involvement conditions) the subjects then read a 120-word biographical statement about the source of the communication they were to read next. One of the biographical statements described the source as a medical authority who was recognized as an expert on the issue of chest $X$ rays and tuberculosis. The other statement described the source as a medical quack who had served a prison term for medical fraud and who knew nothing substantial about the issue, but had written the communication for a magazine catering to sensationalism.

Communication plansibility. After receiving the biographical information about the source, the subjects then read a 350-word communication attributed to the source. One communication presented rather plausible evidence against the use of the chest $\mathrm{X}$ ray, citing scientific evidence from experiments as to the effects of radiation as well as presenting evidence for the superiority of the skin test as a means of detection. The other communication stated that a survey had been undertaken to ascertain if chest $\mathrm{X}$ rays had any adverse effects. Out of 800 respondents in the survey, 4 persons stated they had aftereffects. The responses of these four persons were briefly stated and constituted rather implausible evidence for a ban on chest $X$ rays; for example, one elderly woman said she had lost her appetite in recent years and thought it might be related to the taking of a chest $X$ ray, and one woman blamed her divorce on her husband's taking a chest $\mathrm{X}$ ray. Both communications ended with the same conclusion which stated that chest $X$ rays should be taken rarely and preferably not at all. Both communications were brief and were designed to be easily understood.

\section{Procedure}

After receiving the test booklet, subjects read the purpose of the experiment (ego-involvement conditions) and then read the biographical information concerning the source. They then responded to a scale designed to assess their impressions of the source's credibility on the issue. This was a nineposition scale ranging from "I would consider him completely incompetent to render an opinion on this matter" to "I would accept his judgment on this matter with question." The subjects then read the communication attributed to the source. After reading the communication the subjects responded to a fouritem questionnaire designed to assess their attitudes on the issue. This questionnaire was taken from McGuire (1961) and presents statements such as "Chest $\mathrm{X}$ rays should be taken regularly and often," and the respondent indicates his degree of agreement with each statement on a 15-point bipolar scale. After 
TABLE 1

Means and Intercorreitations between Source Creprbility, Subject Attitude, Perceived Source Attrtude, and Recali for the Eight TreatMent Groups

\begin{tabular}{|c|c|c|c|c|c|c|c|}
\hline \multirow[b]{2}{*}{ Treatments } & \multicolumn{4}{|c|}{$M$} & \multicolumn{3}{|c|}{ Intercorrelations } \\
\hline & $\begin{array}{l}\text { Source } \\
\text { credi- } \\
\text { bility }\end{array}$ & $\begin{array}{l}S \text { atti- } \\
\text { tude }\end{array}$ & $\begin{array}{l}\text { Perceived } \\
\text { source } \\
\text { attitude }\end{array}$ & $\%$ recall & $\begin{array}{c}S \text { attitude } \\
\text { and source } \\
\text { attitude }\end{array}$ & $\left|\begin{array}{c}S \text { attitude } \\
\text { and recall }\end{array}\right|$ & $\begin{array}{c}\text { Source } \\
\text { attitude } \\
\text { and re- } \\
\text { call }\end{array}$ \\
\hline \multicolumn{8}{|l|}{ High ego-involvement } \\
\hline Plausible communication-High source & 7.00 & 31.04 & 10.76 & 60.92 & .36 & -.32 & $-.73^{*}$ \\
\hline Plausible communication-Low source & 3.44 & 33.64 & 10.76 & 61.04 & .37 & $-.40^{*}$ & -.20 \\
\hline Implausible communication-High source & 7.40 & 44.48 & 23.32 & 59.60 & 0 & -.22 & .15 \\
\hline Implausible communication-Low source & 3.56 & 43.60 & 16.32 & 60.88 & .13 & -.21 & -.06 \\
\hline \multicolumn{8}{|l|}{ Low ego-involvement } \\
\hline Plausible communication-High source & 7.60 & 22.52 & 9.60 & 56.76 & .22 & $-.51^{*}$ & -.23 \\
\hline Plausible communication-Low source & 3.64 & 31.00 & 9.56 & 61.28 & $.43^{*}$ & .18 & -.02 \\
\hline Implausible communication-High source & 7.20 & 38.84 & 17.40 & 59.24 & .02 & $.51^{*}$ & -.08 \\
\hline Implausible communication-Low source & 3.52 & 45.24 & 17.56 & 64.12 & -.24 & .10 & -.29 \\
\hline
\end{tabular}

Note. $-n=25$ in all treatments.

a The lower the score, the more attitude change.
.

filling out the attitude questionnaire the subjects were given a second (and similar) questionnaire and asked to fill it out as they thought the source would fill it out. On the last page of the test booklet the subjects answered a questionnaire designed to assess their recall of the communication. This questionnaire consisted of sentences taken from the communication. Parts of the sentences were ommitted and subjects were asked to recall the missing words or phrases.

To insure as random an assignment of subjects to treatments as possible, the test booklets representing the 10 treatments were "shuffled" before they were passed out to the subjects. Thus, within the limits of the design, the assignment of subjects to treatments was random, and the experimenter had no knowledge of which subjects had been assigned to which treatments.

\section{RESULTS}

Source manipulation. Initial ratings of source credibility were made on a 9-point scale with 9 being the most favorable score possible. Table 1 reports the average ratings of source for the eight treatment groups. Table 2 presents the results of a $2 \times 2 \times 2$ analysis of variance (Source $\times$ Plausibility $\times$ Ego-Involvement Conditions) performed on these data. The only significant source of variance is a highly significant effect due to the source manipulation, thus indicating the success of this manipulation.

Attitude change. Posttreatment attitude was measured on a four-item scale. The range of

TABLE 2

Analyses of Variance of Source Credibility, Subject Attitude, Perceived Source Attitude, and Recal.l Measures

\begin{tabular}{|c|c|c|c|c|c|c|c|c|}
\hline \multirow{2}{*}{ Source } & \multicolumn{2}{|c|}{ Source credibility } & \multicolumn{2}{|c|}{$S$ attitude } & \multicolumn{2}{|c|}{ Source attitude } & \multicolumn{2}{|c|}{ Recall } \\
\hline & $M S$ & $F$ & $M S$ & $F$ & $M S$ & F & $M S$ & $F$ \\
\hline Ego-involvement (A) & .98 & & 718.20 & $4.01 *$ & 154.88 & & 48.02 & \\
\hline Source credibility $(B)$ & 706.88 & $450.87 *$ & 861.12 & $4.81^{*}$ & 147.92 & & 196.02 & \\
\hline Communication plausibility (C) & 0 & & $9,099.00$ & $50.82 *$ & $3,595.52$ & $22.16^{*}$ & 2.88 & \\
\hline$A \times B$ & .18 & & 541.21 & $3.02^{* *}$ & 158.42 & & 72.00 & \\
\hline$A \times C$ & 3.38 & 2.13 & 68.44 & & 16.82 & & 40.50 & \\
\hline$B \times C$ & 0 & & 96.61 & & 144,50 & & 8.82 & \\
\hline$A \times B \times C$ & .98 & & 97.77 & & 162.02 & & 42.32 & \\
\hline Within & 1.59 & & 179.03 & & 162.24 & & 364.14 & \\
\hline
\end{tabular}

$* p<10, d f=1 / 192$ 
TABLE 3

Mean Posttreatment Subject Attitude Scores for SoURCe AND Ego-Involvfatent TREATMENTS

\begin{tabular}{c|c|c} 
Treatnent & High source & Low source \\
\hline Low ego-involvement & 30.68 & 38.12 \\
High ego-involvement & 37.76 & 38.62 \\
\hline
\end{tabular}

Note.-The lower the score the greater the attitude change. $N=50$ in each cell.

possible scores is 4-60 with a low score indicating more attitude change toward the communication. Table 1 presents the mean posttreatment attitude scores for the eight treatment groups, and Table 2 reports the analysis of variance performed on these data. As this latter table indicates there was less attitude change under high-ego-involvement conditions, less attitude change to the low credibility source, and less attitude change to the implausible message. The Source $\times$ Ego-Involvement interaction (Table 3 ) was analyzed by Duncan's multiple-range test (Edwards, 1960) and it was found that the mean attitude change was significantly greater under lowego-involvement-high-source-credibility conditions than each of the other three combinations of source credibility and ego-involvement conditions $(p<.01)$. However, these latter three combinations did not differ significantly from one another. This result is interpreted as supporting the first hypothesis of this study. ${ }^{3}$

3 Two control groups were run in which the subjects reccived either the high-or low-ego-involvement instructions and then filled out the attitude questionnaire. The purposes of these control groups was to provide a no-treatment base line by which to assess whether or not attitude change was occurring in the treatment groups. The mean attitude score for the high critical evaluation group was 48.44 , and the mean for the low critical evaluation control group was 50.32. In order to compare these means with the treatment group means a $2 \times 5$ analysis of variance (ego-involvement conditions versus the four other treatment groups plus the control group) was performed and a Duncan multiple-range test used to compare the various means. The results of this test indicated that the two control group means did not differ significantly from each other nor did they differ from the low-source-implausible-communication means in both ego-involvement conditions and the high-source-implausible-communication mean in the high ego-involvement condition. All other comparisons with the control group means were significant at beyond the .05 level.
A second problem investigated in this study was the effect of communication plausibility on attitude change to the different sources. In the low-ego-involvement and plausible-communication treatment the difference in attitude change to the high and low source was 8.48 scale points. For the implausible communication the difference was 6.40 . Although there is some trend for the difference to be greater for the plausible message, the negligible Source $\times$ Communication effect (in the ANOVA), as well as the negligible three-way interaction, indicates that this trend was quite minor. These results are supportive of the theory postulated by Hovland et al. (1953) in the absence of dissociation effects (see Discussion).

Perceived source attitude. Subjects were asked to estimate how the source would check the attitude scale. The scale used for this measure was the same as used for the subjects attitude. The range of possible scores is $4-60$, with 4 being the position advocated in the communication. This measure probably reflects two things: the subject's comprehension of the communication and the subject's tendency to dissociate the source from the communication. Since the communication in this study was fairly easy to comprehend, we feel that this measure can be viewed as a measure of dissociation. Table 1 reports the means of the eight treatment groups, and Table 2 reports the results of an analysis of variance performed on these data. The only significant effect is due to message plausibility indicating more dissociation for the implausible than the plausible message. No significant dissociation as a function of source was found.

Communication recall. Recall was measured by having subjects fill in missing words or phrases of sentences taken from the communication. There were 15 such blanks for the implausible communication and 20 blanks for the plausible communication. For each blank a score of 2 was given if the answer was exactly as given in the communication, a score of 1 was given if the answer reflected the basic idea given in that sentence in the communication, and a score of 0 was given if the answer was completely wrong. Subjects' recall scores were converted to percentage of possible correct. Table 1 reports the means of 
the eight treatment groups, and Table 2 reports the results of the analysis of variance performed on these data. All sources of variance yield negligible $F$ ratios, which suggests that the manipulations of this experiment had no major effect on the recall of the communication.

Correlational data. Table 1 also presents product-moment correlations between the three posttreatment measures in the eight treatment groups. It is to be noted with respect to the attitude measure that no pretest was given and thus these correlations may not truely reflect the relationship between attitude change and the other two measures. For this reason we are somewhat reluctant to interpret these results and will at this point merely present these data for the readers inspection.

\section{Drscussion}

The results support the theory of source credibility as an evaluative "set" operating primarily under low-ego-involvement conditions. When all subjects are led to evaluate the communication critically (high-ego-involvement conditions), the sources differences in attitude change tend to disappear. Since most attitude change takes place under lowego-involvement conditions, particularly when we attempt to disguise the purpose by calling it a study of impression formation or a study of reading skills, it is not surprising that Insko (1967, p. 48) found source differences to appear so consistently that he did not bother to review the literature. These results have further implications in that much of the attitude-change results (and theory) found in the laboratory may be applicable only to low-egoinvolvement situations, and the more selfinvolving situations are yet to be explored. In this light it is interesting to note that Johnson and Steiner (1968) found little attitude change, regardless of source, when the (negative) communication concerned the subjects' personal traits.

No significant difference was found in attitude change between the high and low source for the plausible condition versus the same two sources in the implausible condition, which supports the Hovland et al. (1953) theory. This theory further states that a high source elicits no greater acceptance of a plausible communication than would occur if the communication were given alone, but the low source lowers the acceptance of the same message. The obverse is true with an implausible message, with the low source having no different effect than would be attained with the communication alone, but the high source raising the acceptance of the communication. Although we have no direct test of these assumptions, the correlations between subject attitude and recall are supportive of these. In the low-ego-involvement and plausible-communication conditions, it was those subjects who apparently read the communication carefully who showed the most attitude change to the high source; whereas, in the implausible condition, it was the subjects who apparently did not read the communication carefully who changed their attitude most to the high source.

The Hovland et al. theory, plus the confirmation of the first hypothesis of this study, seemingly points to a possible integration of the attitude change and social conformity research under a single theory. For example, the Asch-type conformity situation is analogous to our low-ego-involvement, implausible-communication treatment. The "communication" in the Asch situation is quite implausible and by itself would elicit little conformity. Little conformity is observed in these experiments when there is low source pressure, but when high pressure is instituted, the subjects show high rates of conformity (see Johnson, Torcivia, \& Poprick, 1968, for a review of source effects in conformity studies). Thus, as suggested by the theory, conformity to an implausible communication will be no greater under low source pressure than the level of conformity to the communication given alone; however, conformity to an implausible communication under high source pressure will be greater than that to the communication given alone. On the other hand, if high-ego-involvement conditions are instituted in a conformity experiment, the effects of source pressure, as the effects of high source credibility in this experiment, are considerably reduced (Di Vesta, 1959).

\section{REFERENCES}

Di Vesth, F. J. Effects of confidence and motivation on susceptibility to informational social influence. 
Journal of Abnormal and Social Psychology, 1959, 59, 204-209.

Edwards, A. L. Experimental design in psychological research. New York: Holt, Rinehart \& Winston, 1960.

Insko, C. A. Theories of attitude change. New York: Appleton-Century-Crofts, 1967.

Hovland, C. I., Janis, I. L., \& KelLeY, H. H. Communication and persuasion. New Haven: Yale University Press, 1953.

Johnson, H. H., \& Steiner, I. D. The effects of source on responses to negative information about one's self. Journal of Social Psychology, 1968, 74, 215-224.

Johnson, H. H., Torciyia, J. M., \& Poprick, M. A. Effects of source credibility on the relationship between authoritarianism and attitude change. Journal of Personality and Social Psychology, 1968, 9, 179-183.

McGuire, W. J. Resistance to persuasion conferred by active and passive prior refutation of same and alternative counterarguments. Journal of Abnormal and Social Psychology, 1961, 63, 326-332.

(Received October 29, 1968)

\section{Manuscripts Accepted for Publication in the \\ Journal of Personality and Social Psychology}

Selective Interest in Communications that Could Arouse Decisional Conflict: A Field Study of Participants in the Draft-Resistance Movement : Irving L. Janis* and Curt N. Rausch : Department of Psychology, Yale University, 333 Cedar Street, New Haven, Connecticut 06520

Commitment and Experience as Determinants of Assimilation and Contrast: John Thibaut*and Michael Ross: Department of Psychology, University of North Carolina, Chapel Hill, North Carolina 27514.

Relationship between Authoritarianism and Attitude Change as a Function of Source Credibility and Type of Communication: Homer H. Johnson* and Richard R. Izzett: Department of Psychology, Loyola University of Chicago, 6525 North Sheridan Road, Chicago, Illinois 60626.

Prediction of Behavior in Two-Person Games: Robert S. Wyer, Jr.*: Department of Psychology, University of Illinois at Chicago Circle, Box 4348, Chicago, Illinois 60680.

Relative Efficacy of Desentitization and Modeling Approaches for Inducing Behavioral, Affective, and Attitudinal Changes: Albert Bandura, ${ }^{*}$ Edward B. Blanchard, and Brunhilde Ritter: Department of Psychology, Stanford University, Stanford, Calfornia 94305

Social Power and Communication within Families of Disturbed and Nondisturbed Preadolescents: Armand A. Alkire*: Department of Psychology, University of California, Los Angeles, California 90024.

Good Samaritanism : An Underground Phenomenon? Irving M. Piliavin, Judith Rodin, and Jane Allyn Paliavin* :

Department of Psychology, University of Pennsylvania, 3813-15 Walnut Street, Philadelphia, Pennsylvania 19104.

Defensive Attribution : Effects of Severity and Relevance on the Responsibility Assigned for An Accident: Kelly G. Shaver*: Department of Psychology, College of William and Mary, Williamsburg, Virginia 23185.

Effect of Threats to Attitudinal Freedom as a Function of Agreement with the Communicator: Stephen Worchel and Jack W. Brehm*: Department of Psychology, Duke University, Durham, North Carolina 27706.

Testing the Self-Perception Explanation of Dissonance Phenomena: On the Salience of Premanipulation Attitudes: Daryl J. Bem* and Keith McConnell; Department of Psychology, Carnegie-Mellon University, Schenley Park, Pittsburgh, Pennsylvania 15213.

Effects of Free versus Constrained Behavior on Attraction between People: Charian Nemeth*: Department of Psychology, University of Chicago, Chicago, Illinois 60637.

Effect of Hypnotic Susceptibility on Creativity Test Performance: Denneth S. Bowers* and Sandra J. van der Meulen: Department of Psychology, University of Waterloo, Waterloo, Ontario, Canada.

On the Description of Subcultural Lexicans: A Multidimensional Approach: Michael L. Friendly* and Sam Glucksberg: c/o Ferman Rfron, Department of Psychology, Princeton University, Princeton, New Jersey 08540 .

A Behavioral Analysis of Teacher Expectancy Effect: Donald H. Meichenbaum, ${ }^{*}$ Kenneth S. Bowers, and Robert R. Ross: Department of Psychology, University of Waterloo, Waterloo, Ontario, Canada.

Convergent-Discriminant Validation and Factor Analysis of Five Scales of Liberalism-Conservatism: Jack M. Hicks and John H. Wright*: Vision Laboratories, 109 Park Avenue, Box X, Oriskany, New York 13424.

Recognition for Faces of Own and Other "Race": Roy S. Mnlpass* and Jerome Kravits: Department of Psychology, University of Illinois, Urbana, Illinois 61801.

Temporal Factors and Cognitive Mediators of Stress Reaction: Carlyle H, Folkins*: Department of Psychology, University of California, Berkeley, California 94720.

What Reinforces in a Social-Reinforcement Situations: Words or Expressions: Howard Leventhal* and Kurt Fischer: Department of Psychology, University of Wisconsin, Madison, Wisconsin 53706.

Effects of Modification of Cognitive Style on Creative Behavior: Vivian Renner*: Department of Psychological Services, Memorial University of Newfoundland, St. John's, Newfoundland, Canada.

\footnotetext{
*Asterik indicates author for whom address is supplied.
} 